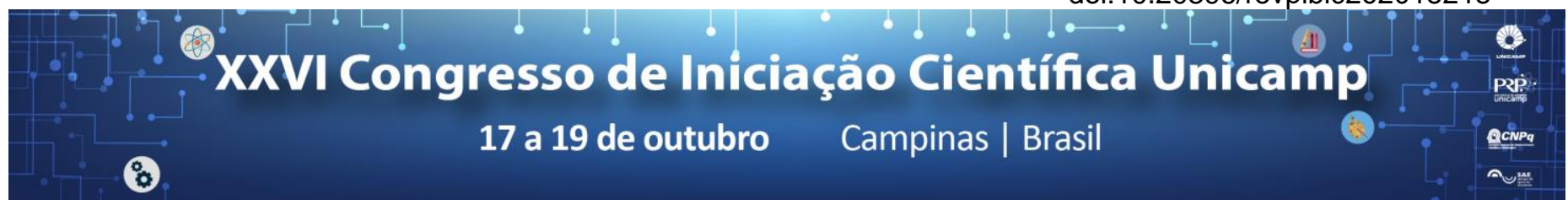

\title{
Análise da Metodologia de Desenvolvimento de Jogos e do jogo Hemotion
}

\section{Breno Martins do Nascimento*, Marcos A. F. Borges.}

\section{Resumo}

O jogo educativo Hemotion tem o objetivo de ensinar comportamentos adequados a crianças hemofílicas em relação à doença. Uma mudança na plataforma de desenvolvimento do jogo fez-se necessária para que ele pudesse continuar acessível, uma vez que a plataforma antiga estava sendo descontinuada. Para essa transição, seguiu-se uma metodologia de desenvolvimento de jogos que, por sua vez, estava em processo de desenvolvimento. Esse projeto buscou analisar os problemas da nova versão do jogo e a eficácia da metodologia de desenvolvimento utilizada.

\section{Palavras-chave:}

Serious Games, Metodologia de Desenvolvimento, Hemofilia.

\section{Introdução}

O Hemotion é um jogo educativo no qual é ensinado para crianças hemofílicas algumas práticas seguras que devem ser seguidas no dia-a-dia sendo portador da doença. O objetivo do jogo é ajudar João a fazer escolhas corretas em relação à hemofilia durante uma semana ${ }^{1}$.

A plataforma em que a primeira versão do jogo foi desenvolvida foi o Flash. Porém, o Flash será descontinuado pela sua fabricante ${ }^{2}$. Fez-se necessária a transposição do jogo para outra plataforma, a Unity. Para essa transição, foi seguida uma metodologia de desenvolvimento de jogos sérios que ainda está em processo de finalização, e, portanto, não havia como confirmar a eficácia da mesma.

Este projeto analisou as versões antiga (Flash) e atual (Unity) do jogo para verificar se algo foi perdido na conversão e para propor melhorias. Foi analisada também a metodologia de desenvolvimento utilizada, para identificar se ela trouxe benefícios para o desenvolvimento da nova versão do jogo. No processo de desenvolvimento dessas melhorias foi possível analisar $o$ quanto a nova metodologia ajuda na continuidade de projetos de construção de jogos no contexto acadêmico.

\section{Resultados e Discussão}

A metodologia desenvolvida cumpre o papel que se propõe, guiando o desenvolvimento dos jogos sérios, de modo que o desenvolvedor saiba quais são os próximos passos a serem seguidos. Ela segue boas práticas de engenharia de software, como 0 desenvolvimento iterativo, desenvolvimento baseado em testes, entrega contínua, criação de protótipos e modelos e a definição de um processo de desenvolvimento logo no início.

O modelo da metodologia contém exemplos ou instruções de preenchimento em todos os campos onde elas são necessárias, 0 que facilita e agiliza 0 preenchimento dos mesmos. Essa documentação será muito benéfica a curto e longo prazo, para eventuais manutenções e atualizações nos jogos nos quais ela for aplicada. A padronização da documentação é mais uma vantagem trazida pela metodologia.
Diversos problemas do jogo foram identificados assim como as sugestões de melhoria foram propostas. Vários desses problemas estavam relacionados aos minigames presentes no jogo, como por exemplo o jogo da velha que não mostrava o vencedor corretamente, travava ao empatar e não possuía opção para jogar novamente.

Ao final do jogo, a quantidade de medalhas (medida do desempenho do jogador) estava sendo mostrada incorretamente. Essas e outras correções e sugestões de melhoria foram aplicados.

\section{Conclusões}

Foi possível perceber as dificuldades que uma criança hemofílica enfrenta em sua vida na realização de tarefas cotidianas. Portanto, o jogo Hemotion tem uma enorme importância ao auxiliar o aprendizado delas.

O projeto também mostrou, na prática, a importância da utilização de um padrão de documentação em um projeto, para que os resultados obtidos não sejam perdidos. A metodologia de desenvolvimento de jogos sérios agiliza muito o processo de documentação ao fornecer um modelo de documentação ao desenvolvedor com todos os pontos essenciais que devem ser registrados. Ela também facilita a utilização do jogo em ambiente educacional, deixando claro sobre o que se trata o jogo e quais as bases educacionais do mesmo.

\section{Agradecimentos}

Gostaria de agradecer ao professor Marcos Augusto Francisco Borges e à PIBIC pela oportunidade de realizar esse projeto, e ao William Rodrigues por todo o apoio com a metodologia. Graças a isso pude ter contato com a metodologia de desenvolvimento e outras ferramentas novas, que contribuirão muito para o meu desenvolvimento profissional.

${ }^{1}$ Pereira Junior, Antonio Alberto; Proposta de nova versão ao jogo Hemotion; Relatório final de Iniciação Científica; FT-UNICAMP, 2017.

${ }^{2}$ Paulella, Vitor Eduardo Lopes; Avaliação de melhorias e ajuste de plataforma no Hemotion; Relatório final de Iniciação Científica; FT-UNICAMP, 2016. 